\title{
PUSAT INFORMASI PADA PERUSAHAAN DAERAH AIR MINUM (PDAM) KOTA PADANG BERBASIS WEB
}

\author{
Harkamsyah Andrianof \\ Universitas Putra Indonesia YPTK Padang \\ harkamsyah.andrianof@upiyptk.ac.id
}

\begin{abstract}
Abstrak
Pemanfaatan teknologi informasi pada PDAM Padang belum optimal, tidak terkecuali pada pengolahan informasi kepada pelanggan yang masih manual. Sehingga menyebabkan informasi yang dibutuhkan tidak efektif dan efesien. Jadi dari hal tersebut penulis mencoba memberikan solusi dengan membangun sebuah sistem informasi pengolahan informasi serta proses transaksi pembayaran tagihan PDAM yang bertujuan untuk membantu atau mempermudah admin dalam melakukan pengolahan data informasi dan pelanggan dalam memperoleh informasi serta mengetahui tarif pembayaran.

Penelitian perpustakaan dan penelitian laboratorium dimana data-data yang diperoleh dikelompokkan terlebih dahulu lalu dalam analisa dan hasil yang digunakan adalah Unified Modelling Language (UML) yang mana diantaranya, Use Case Diagram, Class Diagram, Sequence Diagram, Aktivity Diagram, Collaboration Diagram, dan Deployment Diagram dan aplikasi yang dibangun menggunakan bahasa pemrograman HTML dan PHP Skrip. Sedangkan database yang dipakai adalah MySQL. Dengan pemanfaatan sistem komputerisasi diharapkan penerapan forum e-raport ini nantinya akan maтри mempermudah guru dan siswa dalam proses penilaian hasil pembelajaran serta dalam mendapatkan informasi yang lebih baik dan berkualitas. Sehingga tujuan yang diharapkan untuk kemajuan siswa dan sekolah dapat tercapai
\end{abstract}

Kata Kunci : Sistem Informasi, pengolahan PDAM, tagihan,

\section{PENDAHULUAN}

\subsection{Latar Belakang}

Sekarang ini informasi yang dibutuhkan oleh suatu perusahaan atau instansi sering ditemui dalam jumlah besar, dan informasi tersebut harus bisa diakses dengan cepat dimana saja dan kapan saja, sehingga suatu sistem tersebut hendaknya online agar dapat mempermudah penyelesaian suatu proses pengerjaan. Untuk itu perlu suatu sistem aplikasi berbasis website dalam pengolahan data yang menggunakan peralatan modern sebagai penunjangnya. Salah satu contohnya yaitu komputer, yang dapat menangani pengolahan data dalam jumlah yang sangat besar, kompleks serta memperkecil kesalahan yang dilakukan.

Sebuah perusahaan atau instansi hendaknya mempunyai sebuah rancangan sistem informasi yang sesuai dengan kebutuhan sehingga dapat menghasilkan informasi yang bernilai tinggi dan dapat digunakan dalam proses pengambilan keputusan. Begitu juga dengan Perusahaan Air Minum Daerah merupakan salah satu instansi pemerintah yang memberikan pelayanan kepada masyarakat khususnya dalam hal pelayanan publik supaya memenuhi kebutuhan masyarakat. Dengan adanya aplikasi berbasis website ini dapat memberikan pelayanan serta informasi kepada masyakarat yang hendak mengetahui tentang profil suatu 
perusahaan dan informasi penting lainya dapat mengakses melalui website tanpa harus mengunjungi sehingga dapat mempermudah masyakarat didalam mendapatkan informasi.

Sebagaimana telah kita ketahui sistem informasi yang dibutuhkan saat sekarang ini ialah informasi yang cepat dan tepat guna sehingga menghasilkan informasi yang bermanfaat. Hal ini juga terjadi ditempat penulis melakukan penelitian, PDAM payakumbuh selama ini belum menggunakan aplikasi berbasis website dalam pengolahan data pelanggan PDAM Padang, sistem informasi pengolahan data yang bersifat manual akan dikomputerisasikan menggunakan website. Melihat latar belakang tersebut maka judul yang diambil adalah "PUSAT INFORMASI PADA PERUSAHAAN DAERAH AIR MINUM(PDAM) KOTA PADANG BERBASIS WEB”

\subsection{Perumusan Masalah}

Berdasarkan dengan latar belakang dari pemilihan judul di atas, maka dapat disimpulkan beberapa masalah yang dapat diambil yaitu sebagai berikut:

1. Apakah dengan adanya sistem informasi berbasis web pada perusahaan daerah air minum dapat membantu dalam memperoleh informasi tagihan dengan cepat dan akurat?

2. Apakah dengan adanya aplikasi berbasis web dapat meningkatkan pelayanan kepada pelanggan perusahaan daearah air minum?

3. Apakah aplikasi sistem informasi berbasis web yang dibangun dengan pemograman PHP dan database MySQL dapat meminimalkan kesalahan dalam pengelolahan data, baik data pelanggan maupun data tagihan pelanggan?

\section{LANDASAN TEORI}

\subsection{Konsep Dasar Sistem Informasi}

Perlunya informasi digunakan oleh pimpinan atau manager sebagai media alat bantu dalam pengambialan keputusan, tidak hanya itu tetapi informasi juga digunakan sebagai alat untuk mengetahui perkembangan di lingkungan serta untuk merencanakan strategi untuk yang akan datang.

\subsubsection{Pengertian Sistem}

Sistem adalah Suatu kumpulan dari

komponen, yang terorganisir, saling berhubungan satu dengan yang lainnya, membentuk satu kesatuan untuk mencapai tujuan tertentu. (Jogiyanto. Sistem Teknologi Informasi, 2009: 34).

Dalam memahami dan mendefenisikan suatu sistem terdapat dua pendekatan yang dapat digunakan untuk menerangkannya, yaitu:

1. Pendekatan prosedur

Sistem adalah kumpulan dari prosedur- prosedur yang mempunyai tujuan tertentu.

2. Pendekatan yang menekankan pada komponen

Sistem adalah kumpulan dari komponen yang saling berhubungan satu dengan yang lainnya membentuk satu kesatuan untuk mencapai tujuan tertentu.

Kedua komponen ini lebih menekankan pada prosesnya, yang mana pendekatan prosedur akan lebih mengena untuk menggambarkan sistem tersebut. sedangkan pendekatan komponen merupakan pendekatan yang relatif baik digunakan untuk menjelaskan suatu sistem informasi. 


\subsubsection{Pengertian Informasi}

sudah

Secara umum sistem informasi dapat diartikan sebagai hasil pengolahan data yang

memiliki arti dan nilai bagi penggunanya adapun pengertian sistem informasi menurut (Abdul Khadir, 2013: 8) sebagai berikut: "Sejumlah komponen (manusia, komputer, teknologi komputer, dan prosedur kerja), ada sesuatu yang diproses (data menjadi informasi), dandimaksudkan untuk mencapai suatu sasaran atau tujuan".

\subsection{Alat Bantu Perancangan Sistem}

Langkah-langkah yang dilakukan pada tahap merancang suatu sistem informasi dan program adalah membuat usulan pemecahan masalah secara logikal sesuai dengan permasalah yang ada. Dan alat bantu yang digunakan dalam membantu pemecahan masalah dalam membuat sistem ini antara lain adalah:

\subsubsection{UML (Unified Modelling Language)}

Unified Modelling Language(UML)adalah salah satu standar bahasa yang banyak digunakan di dalam dunia industri untukmendefinisikan berbagai requirement, membuat analisis dan desain, serta menggambarkan arsitektur dalam pemrograman berorientasi objek. (Rosa A.SM.Shalahuddin, rekayasa perangkat lunak. 2013:133).

\subsubsection{Jenis-jenis Diagram UML}

Berikut adalah beberapa jenis diagramyang digunakan dalam pembuatan diagram UML:

\subsubsection{Use Case Diagram}

Use case diagram adalah: pemodelan untuk kelakuan (behavior) sistem informasi yang dibuat. (Rosa A.S-M.Shalahuddin, rekayasa perangkat lunak. 2013: 137).

\subsubsection{Class Diagram}

Class diagram adalah struktur sistem dari

segi pendefinisian kelas-kelas yang akan dibuat untuk membangun sistem. (Rosa A.S-M. Shalahuddin, rekayasa perangkat lunak. 2013: 141).

\subsubsection{Activity Diagram}

Activity diagram adalah menggambarkan workflow (aliran kerja) atau aktivitas dari sebuah sistem atau proses bisnis atau menu yang ada pada perangkat lunak. Dan activity diagram juga menggambarkan berbagai alir aktivitas dalam sistem yang sedang dirancang. (Rosa A.S-M. Shalahuddin, rekayasa perangkat lunak. 2013: 16

\subsubsection{Sequence Diagram}

Sequence diagram menggambarkan

kelakuan objek pada use case dengan mendeskripsikan waktu hidup objek dan message yang dikirimkan dan diterima objek. (Rosa .A.S-M. Shalahuddin, rekayasa perangkat lunak. 2013: 165).

\subsubsection{Collaboration Diagram}

Collaboration diagram juga menggambarkan interaksi antar objek seperti sequence diagram, tetapi lebih menekankan pada peran masing-masing objek dan bukan pada waktu penyampaian message, setiap message memiliki sequence number, di mana message dari level tertinggi memiliki nomor 1. Message dari level yang sama memiliki prefiks yang sama 


\section{MAJALAH ILMIAH}

\subsubsection{Deployment Diagram}

Deployment atau physical diagram menggambarkan detail bagaimana komponen di deploy dalam infrastruktur sistem, di mana komponen akan terletak (pada mesin, server atau piranti keras apa), bagaimana kemampuan jaringan pada lokasi tersebut, spesifikasi server, dan hal-hal lain yang bersifat fisikal.

\subsection{Konsep Dasar PHP dan MYSQL}

Dalam sub bab ini akan dibahas tentang konsep dasar PHP dan MYSQL, yang merupakan alat bantu perangkat lunak (software) yang membantu dalam pembentukan sistem. graman

\subsubsection{PHP}

PHP adalah akronim dari PHP Hypertext Preprocessor yaitu suatu bahasa pemrograman berbasiskan kode-kode (script) yang digunakan untuk mengolah suatu data dan mengirimkannya kembali ke web browser menjadi kode HTML. (oktavian Diar Puji, membuat website powerfull menggunakan PHP. 2013: 69)

\subsection{MySQL}

MySQL adalah sebuah implementasi dari sistem manajemen basisdata relasional

(RDBMS) yang didistribusikan secara gratis dibawah lisensi GPL (General Public License). Setiap pengguna dapat secara bebas menggunakan MySQL, namun dengan batasan perangkat lunak tersebut tidak boleh dijadikan produk turunan yang bersifat komersial. MySQL sebenarnya merupakan turunan salah satu konsep utama dalam basisdata yang telah ada sebelumnya. SQL (Structured Query Language). 


\section{ANALISA DAN PERANCANGAN}

\subsection{Analisa Sistem}

Dalam melakukan analisis sistem terlebih

dahulu harus mengetahui dan memahami sistem, untuk menganalisa sistem diperlukan data dari sistem untuk dianalisa. Data yang diperlukan adalah hal-hal yang berkenaan dengan defenisi data.

Adapun kelemahan dari sistem lama yaitu sulitnya pelanggan dalam memperoleh informasi mengenai PDAM, pembayaran, informasi terkait mengenai perusahaan, karena pelanggan perlu mendatangi perusahaan untuk mengetahui profil perusahaan serta tata cara melakukan pendaftaraan PDAM serta informasi penting lainnya.

\subsubsection{Analisa Sistem yang Sedang Berjalan}

Berdasarkan penelitian yang dilakukan secara langsung ke lapangan terhadap sistem yang sedang berjalan pada PDAM Padang, peneliti mengetahui bahwa masih banyak kendala dalam melakukan proses pembayaran dan informasi yang diberikan kepada pelanggan masih kurang efisien dan waktu yang dibutuhkan sangat lama. Jadi dapat diambil kesimpulan bahwa sistem yang sedang berjalan saat ini masih belum berjalan sesuai dengan yang diharapkan dan dibutuhkan suatu sistem penunjang untuk mempermudah dan memperlancar segala kegiatan yang terjadi sehingga tujuan yang telah ditetapkan dapat tercapai.

\subsection{Analisa Sistem PDAM Padang}

1. Admin yang berperan sebagai pengendali sistem melakukan entry home, entry profil, entry contact, entry user yang mencakup menginput data pelanggan dan kasir, input data air, input data pimpinan, input data transaksi pembayaran dan input data pegawai, serta sekaligus mengelola sistem dimana nantinya kasir akan login untuk dapat mengakses system informasi yang tersedia dimana kasir dapat melakukan proses transaksi pembayaran pelanggan PDAM.

2. Data transaksi pembayaran yang di tambahkan oleh kasir tadi dikonfirmasi oleh admin yang mana setelah dikonfirmasi, admin juga dapat melakukan penginformasian data tersebut kepada pimpinan.

3. Pimpinan juga dapat melakukan login sebagai sistem, dan bukan "bagaimana". Sebuah use case merepresentasikan sebuah interaksi antara aktor dengan sistem. Use Case Diagram dari sistem yang dirancang dapat digambarkan

\subsection{Desain Sistem Baru}

Setelah dilakukan penganalisaan terhadap sistem yang sedang berjalan maka desain sistem yang baru perlu dibuat, tujuan

dari sistem baru tersebut adalah penyempurnaan 
dari sistem yang ada. Adapun hal-hal yang perlu dirancang dalam sistem ini tidak terlepas dari bentuk yang telah ada sebelumnya. Dari perancangan terhadap sistem baru ini diharapkan adanya perbaikan dan penyempurnaan dari sistem yang lama, desain sistem baru yang diusulkan MELIPUTI desain sistem secara global yaitu : use case diagram, class diagram, Activity diagram, Sequence diagram, Collaboration diagram, Deployment diagram, struktur program.

\subsubsection{Desain Sistem Secara Global}

Sedangkan desain sistem secara terinci

yang dibagi lagi menjadi desain input dan desain output, desain file dan logika program. Untuk dapat dioperasikan sistem yang baru ini selain dibutuhkan tenaga kerja yang paham dan mengerti dibidang ini juga diharuskan mengoperasikannya dengan baik, sehingga apa yang diharapkan oleh sistem dapat terpenuhi.

\subsubsection{Unified Modeling Language (UML)}

Unified Modelling Language (UML)

adalah salah satu standar bahasa yang banyak digunakan di dunia industri untuk mendefinisikan requirement, membuat analisis dan desain, serta menggambarkan arsitektur dalam pemrograman berorientasi objek. (Rosa A.S-M.Shalahuddin, rekayasa perangkat lunak. 2013:133).

\subsubsection{Use Case Diagram}

sistem,

Use case diagram menggambarkan fungsionalitas yang diharapkan dari sebuah yang ditekankan adalah "apa" yang diperbuat

\subsubsection{Sequence Diagram}

Sequence diagram menjelaskan interaksi

antar objek di dalam dan di sekitar sistem berupa pesan (message) yang disusun dalam suatu urutan waktu yaitu urutan kejadian yang dilakukan oleh seorang aktor dalam menjalankan sistem.

Sequence diagram biasa digunakan untuk menggambarkan skenario atau rangkaian langkah- langkah yang dilakukan sebagai response dari sebuah kegiatan untuk menghasilkan output tertentu.

\section{Sequence Diagram Admin}

Diagram ini menjelaskan urutan langkah-

langkah prilaku yang dilakukan admin secara detail menurut waktu dan pesan yang disampaikan melalui objek di dalam use case

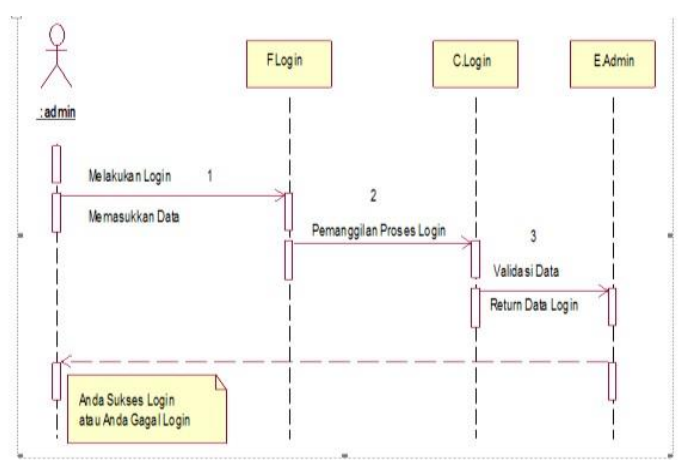




\section{MAJALAH ILMIAH}

\section{Gambar 3.2 Sequence Diagram Admin}

\section{Sequence Diagram Entry Data Kasir}

Sequence diagram entry data kasir menggambarkan proses admin/uses didalam melakukan proses input data kasir, sequence diagram entry data kasir dapat digambarkan seperti pada gambar 3.3.

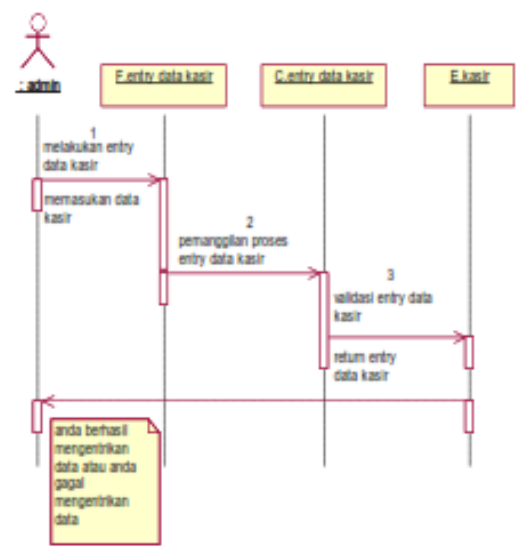

\section{Gambar 3.3 Sequence Diagram Entry Data Kasir}

\section{Sequence Diagram Entry Data Pelanggan}

Sequence entry data pelanggan menggambarkan proses kasir didalam melakukan proses entry data pelanggan yang dapat dilihat pada gambar

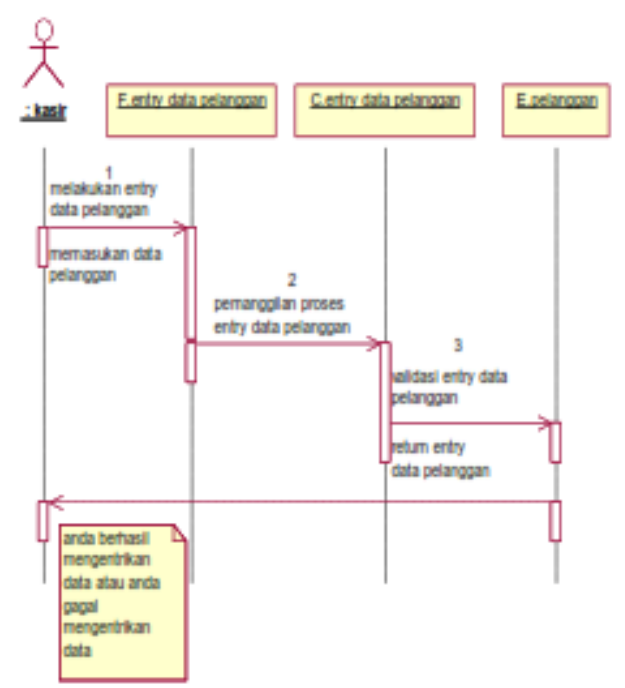

Gambar 3.4 Collaboration Diagram entry Pelanggan

\subsubsection{Collaboration Diagram}

Collaboration diagram juga menggambarkan interaksi antar objek seperti sequence diagram, tetapi lebih menekankan pada peran masing-masing objek 


\section{MAJALAH ILMIAH}

\section{Collaboration Diagram entry kasir}

Collaboration diagram entry kasir menggambarkan proses admin dalam melakukan pilihan dalam input data kasir, edit data kasir, dan hapus data kasir. Collaboration diagram entry kasir dapat dilihat pada gambar 3.5

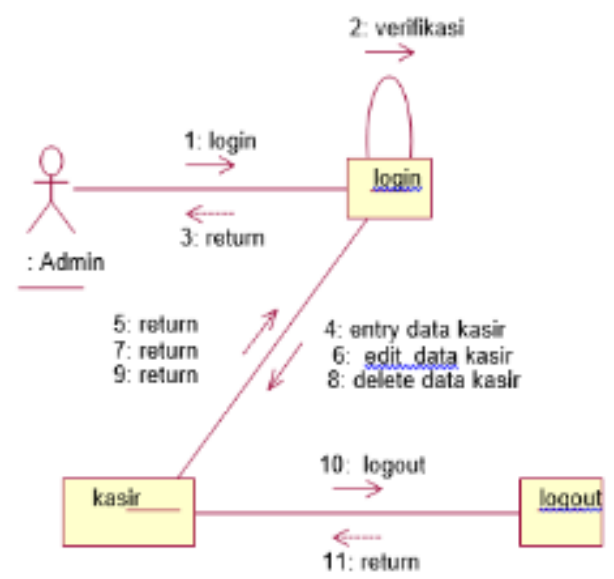

\section{Gambar 3.5 Collaboration Diagram entry kasir}

\section{Collaboration Diagram Entry pembayaran}

Collaboration diagram daftar guru menggambarkan proses admin dalam melakukan pilihan dalam input data guru, edit data guru, tambah data guru, dan hapus data guru. Collaboration diagram daftar guru dapat dilihat pada gambar 3.6

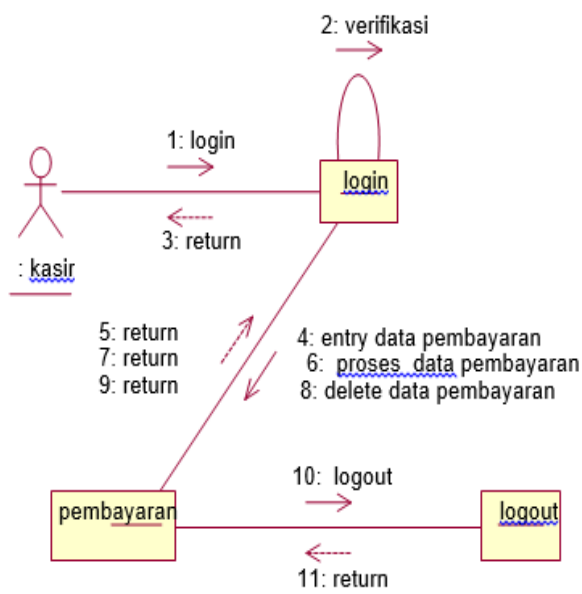

Gambar 3.6 Collaboration Diagram Entry pembayaran

\subsubsection{Activity Diagram}

Merupakan diagram yang menggambarkan berbagai alir aktifitas dalam sistem yang sedang dirancang, bagaimana masing-masing alir berawal, decision yang mungkin terjadi dan bagaimana mereka berakhir. 


\section{MAJALAH ILMIAH}

\section{Aktivity Diagram Admin}

Activity diagram admin menggambarkan proses admin untuk melakukan pilihan entry data kasir, pegawai, informasi, dan tarif air. Activity diagram admin dapat digambarkan seperti pada gambar 3.7

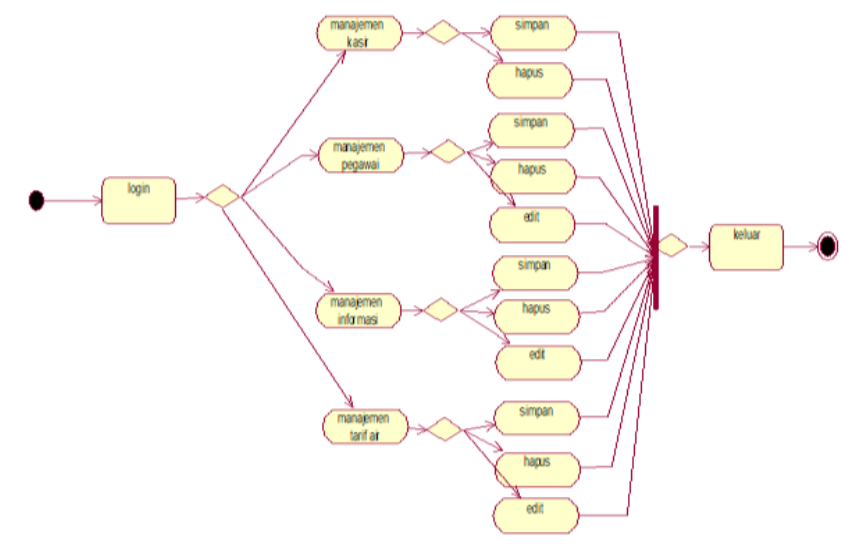

Gambar 3.7 Activity Diagram Admin

\section{Aktivity Diagram kasir}

Activity diagram kasir menggambarkan proses kasir untuk melakukan pilihan entry pelanggan dan entry pembayarn. Activity diagram kasir dapat digambarkan seperti pada gambar 3.8

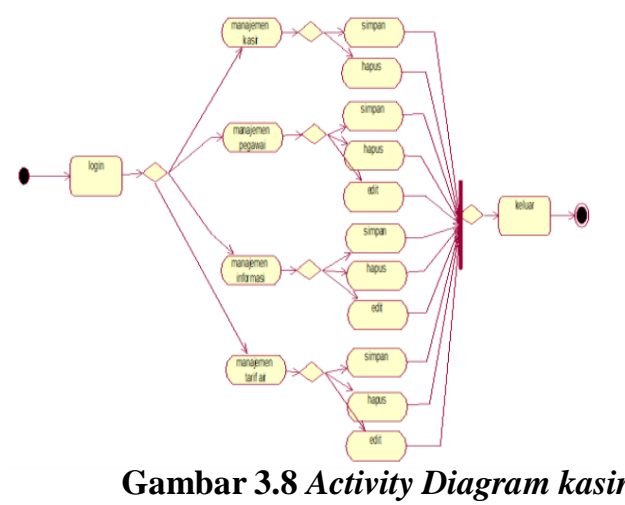

\section{Aktivity Diagram Pimpinan}

Activity diagram pimpinan menggambarkan proses pimpinan untuk melakukan pilihan lihat laporan, Activity diagram pimpinan dapat digambarkan seperti pada gambar 3.9 


\section{MAJALAH ILMIAH}

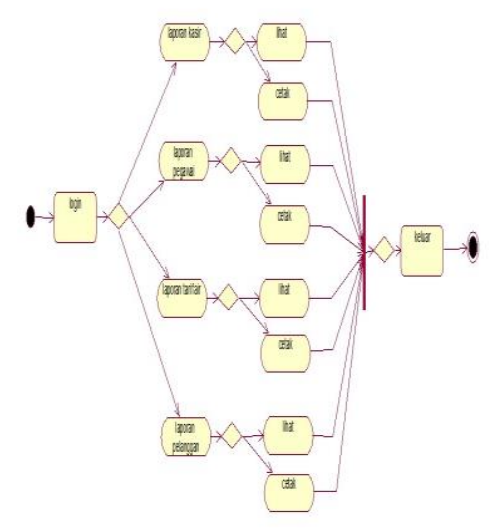

Gambar 3.9 Activity Diagram Guru

\subsubsection{Deployment Diagram}

Deployment/physical diagram menggambarkan detail bagaimana komponen dipecah dalam infrastrukur sistem, dimana komponen akan terletak (pada mesin, server atau piranti keras apa), bagaimana kemampuan jaringan pada lokasi tersebut, spesifikasi server, dan hal-hal lain yang bersifat fisika

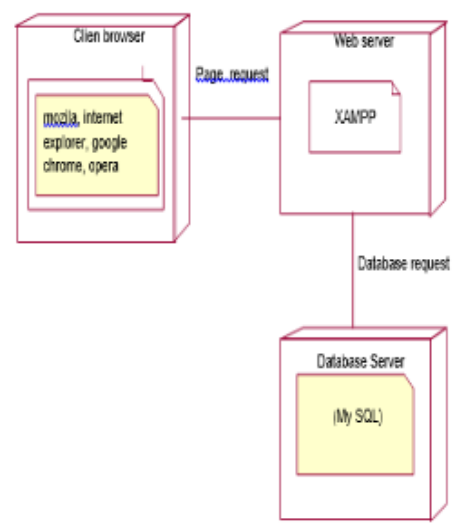

\section{Gambar 3.10 Deployment Diagram}

\subsubsection{Class Diagram}

Class adalah sebuah spesifikasi yang jika diinstansi akan menghasilkan sebuah objek dan merupakan inti dari pengembangan dan desain berorientasi objek. Class diagram dari Analisa dan Penerapan Aplikasi sistem informasi PDAM Padang dapat digambarkan seperti pada gambar 3.11 


\section{MAJALAH ILMIAH}

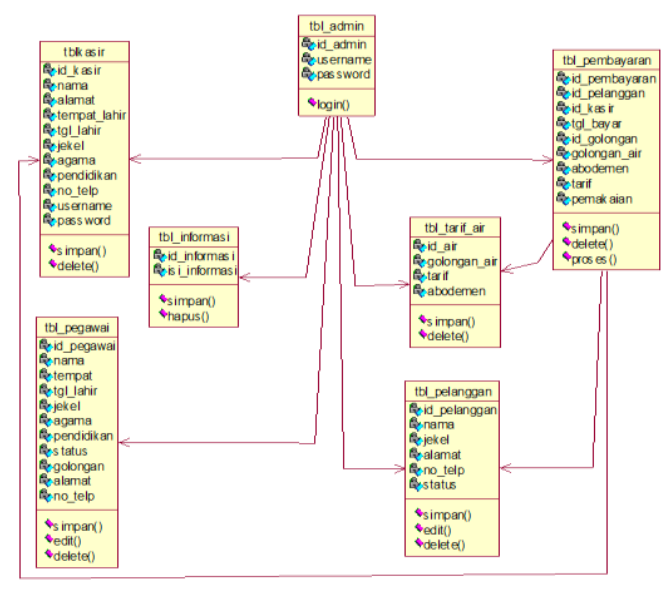

Gambar 3.11 Class Diagram

\section{IMPLEMENTASI DAN PENGUJIAN SISTEM}




\subsection{Implementasi Sistem}

Implementasi sistem merupakan tahap akan sistem supaya siap untuk dioperasikan. am implementasi sistem ada beberapa tahap harus dilakukan diantaranya adalah rapkan rencana implementasi, melakukan implementasi dan tindak lanjut mentasi. Untuk melakukan atau implementasikan program aplikasi yang telah maka diperlukan sebuah alat bantu a komputer, yang mana untuk operasikan komputer itu sendiri yang erlukan tiga buah komponen pendukung hardware, software, dan brainware.

\subsection{Pengujian Instalasi Software}

Pada tahapan ini berisikan hasil program dan penjelasan program yang dibuat untuk mendukung sistem yang telah dirancang. Adapun software yang dibutuhkan dalam pengujian sistem antara lain software Xampp 1.6.8.

1. Pilih bahasa yang digunakan. Lalu klik OK .

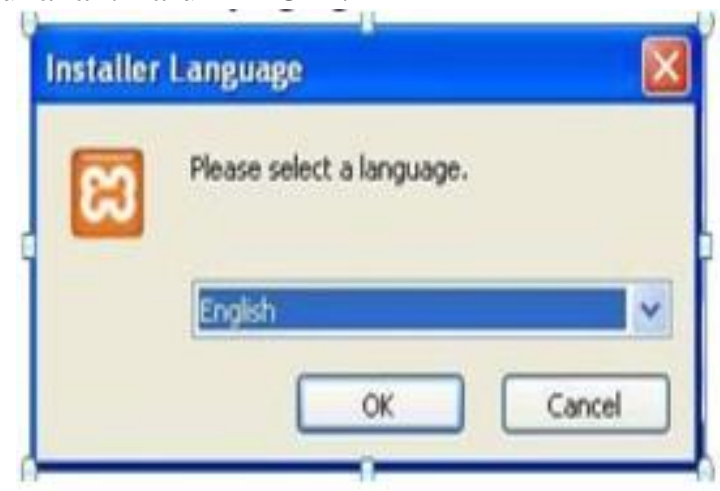

Gambar 4.1 Install Xampp

2. Tunggu proses instalasinya selesai. Jika instalasi sukses, klik "finish". Control panel xampp yang telah berhasil diinstal

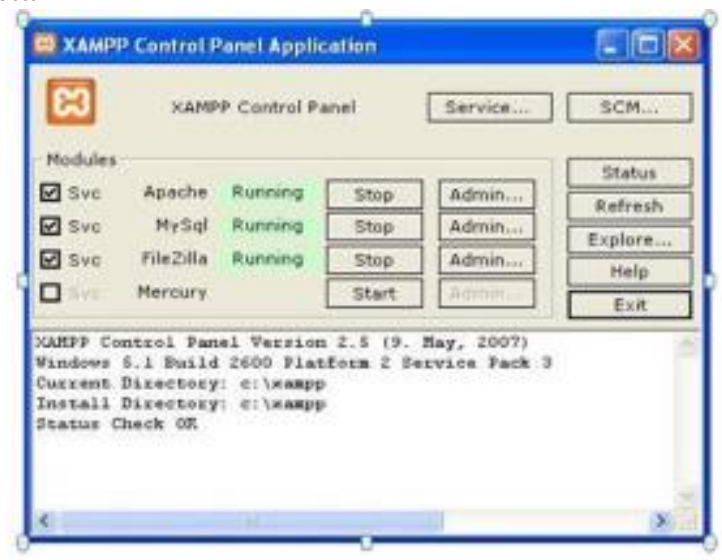

Gambar 4.2 Control panel xampp

\subsection{Pengujian Sistem}

berjalan

Pengujian sistem dilakukan untuk melihat apakah rancangan sistem yang telah dibuat sesuai dengan yang diharapkan. Disini kita dapat melihat hasil dari perancangan sistem yang telah dirancang sebelumnya. 
1. Tampilan Menu Utama

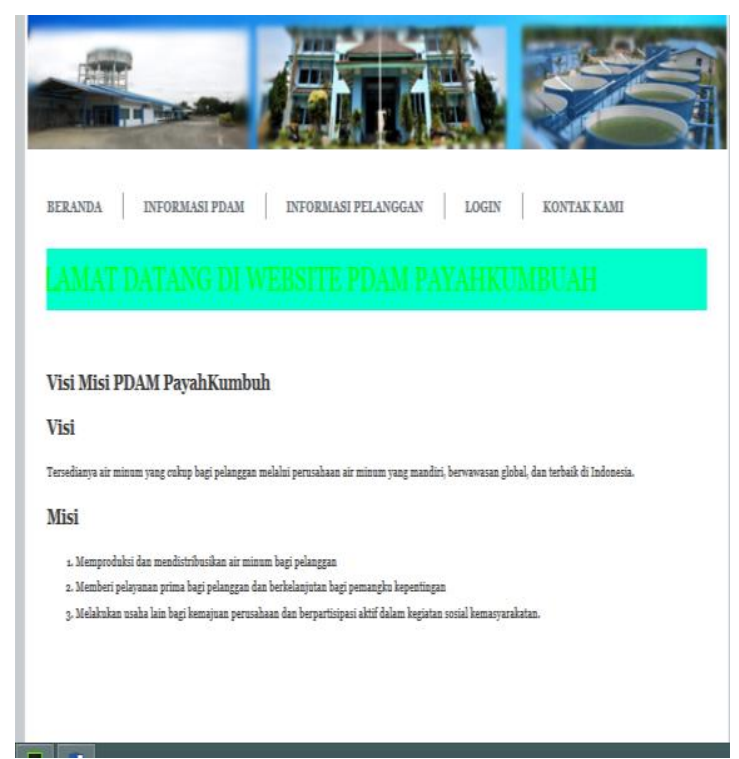

\section{Gambar 4.3 Halaman Home}

2. Tampilan Halaman Profil

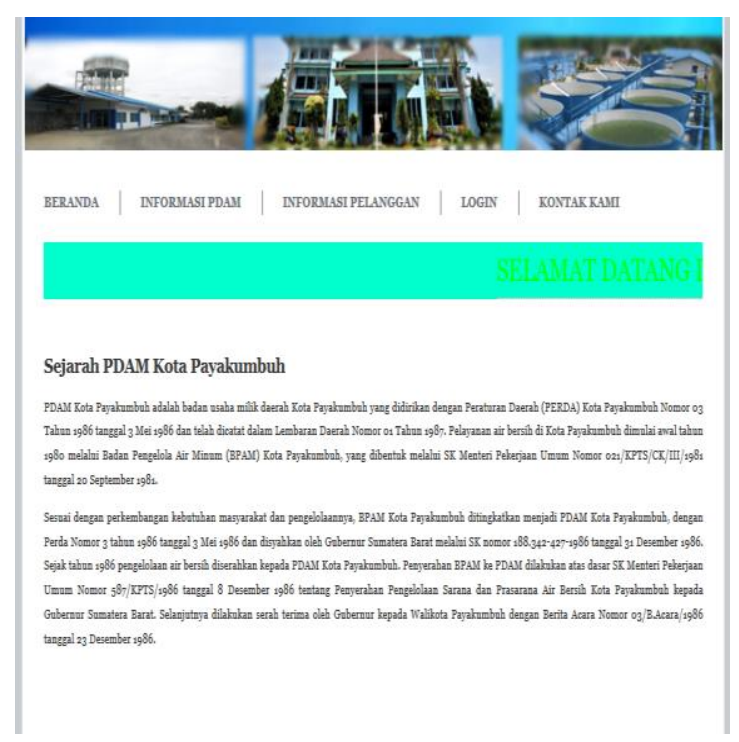

Gambar 4.4 Halaman Profil 
3. Tampilan Halaman Informasi Tarif Air

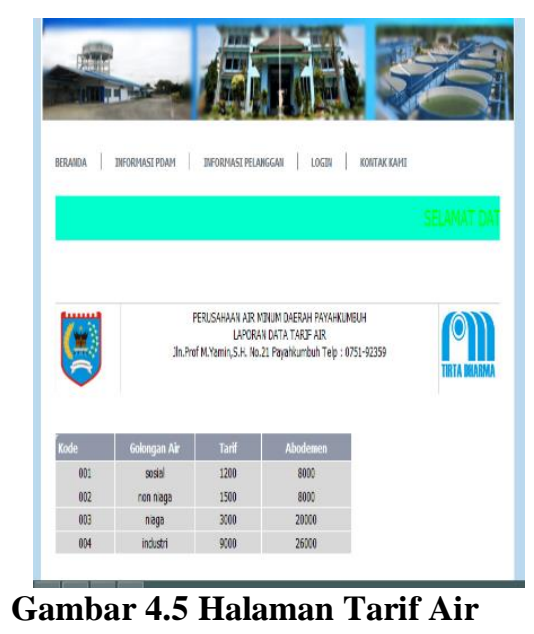

4. Tampilan halaman login

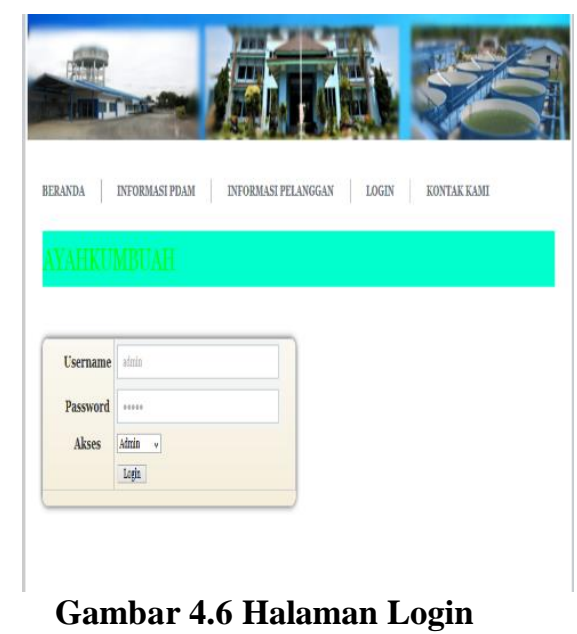

\section{Gambar 4.6 Halaman Login}

5. Tampilan Halaman Admin

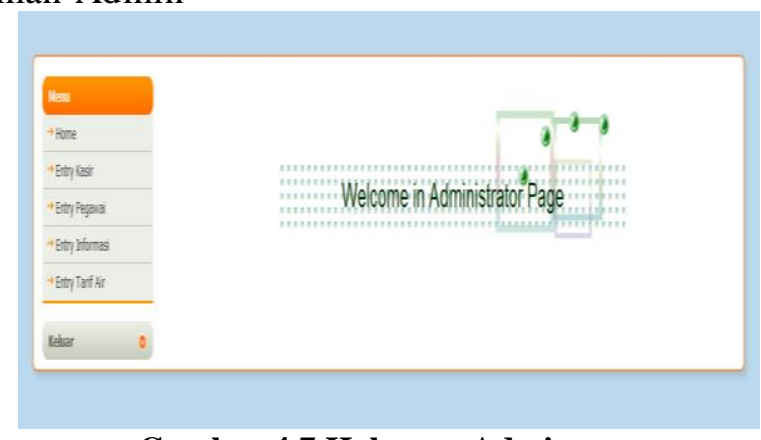

Gambar 4.7 Halaman Admin 


\section{MAJALAH ILMIAH}

6. Tampilan Halaman Daftar kasir

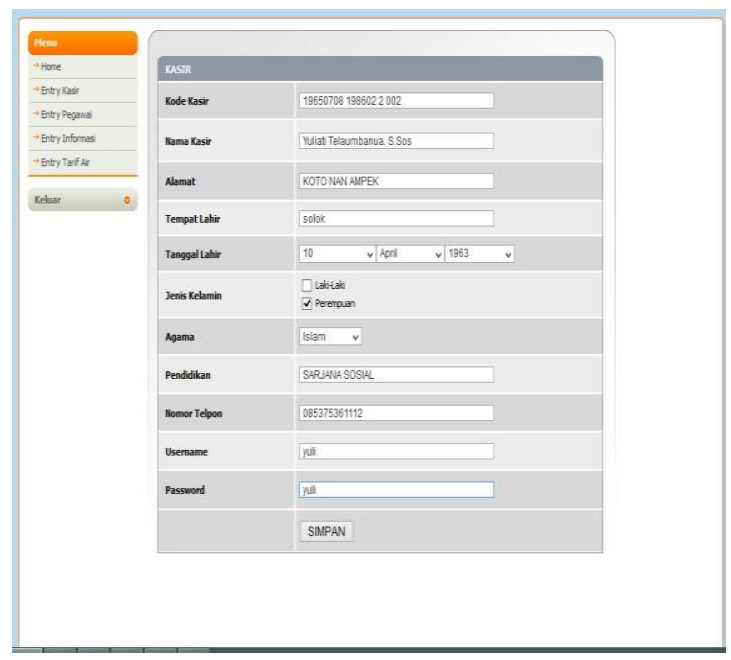

Gambar 4.8 Halaman Daftar kasir

7. Tampilan Halaman Form Informasi

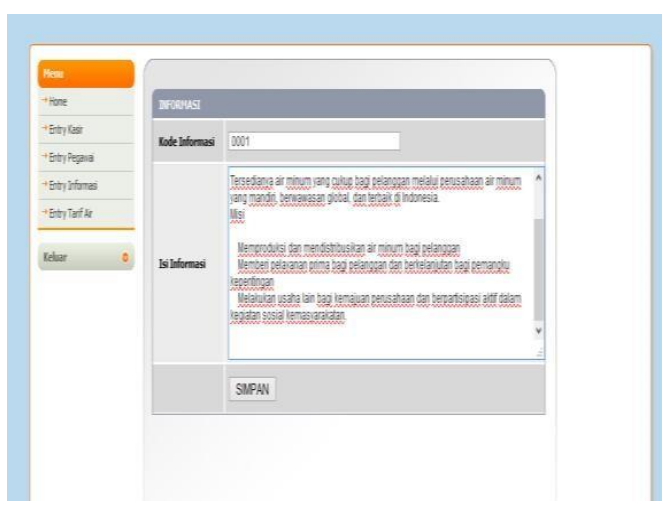

Gambar 4.9 Halaman Form Informasi

8. Tampilan Halaman Form Tarif Air

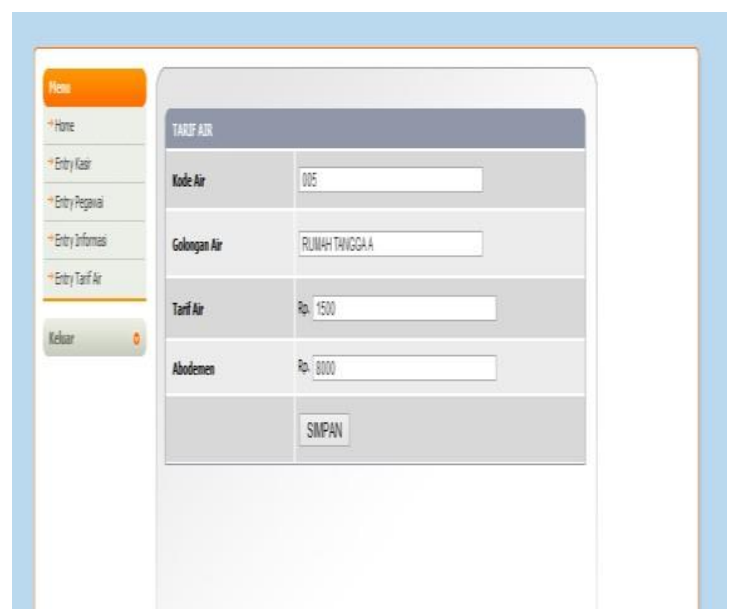

Gambar 4.10 Halaman Entry Pelanggan 
10. Tampilan halaman data pembayaran

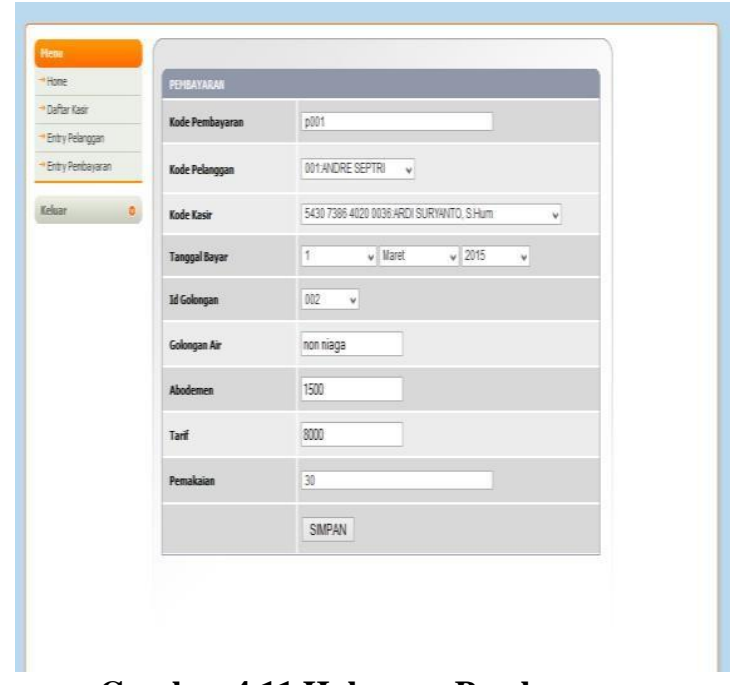

Gambar 4.11 Halaman Pembayaran 


\section{PENUTUP}

\subsection{Kesimpulan}

Berdasarkan proses analisa dan penelitian yang telah dilakukan sebelumnya pada PDAM PADANG khususnya dalam bentuk aktivitas atau kegiatan proses pembayaran dan pemberian informasi terbaru kepada pelanggan maka penulis mencoba untuk menarik kesimpulan dan saran-saran yang dapat menunjang perbaikan dari sistem ini di masa yang akan datang.

Adapun kesimpulan yang dapat ditarik dari pembahasan skripsi ini adalah:

1 Dengan adanya Aplikasi berbasis website

ini, semua pekerjaan jadi lebih mudah dan singkat tanpa adanya terkendala oleh waktu dan pelanggan dapat mengetahui informasi mengenai PDAM tersebut dimana saja.

2 Dengan adanya Aplikasi website ini, admin diharapkan dapat dengan mudah melakukan proses penyimpanan data pelanggan serta informasi-informasi yang berkaitan dengan pelanggan, dan penyampaian informasi oleh admin juga lebih efisien di bandingkan dengan manual.

3 Dengan adanya website ini bagi admin dapat mengelolah data secara cepat dan tidak memerlukan waktu yang lama didalam melakukan proses pembayaran.

\subsection{Saran}

Berdasarkan kesimpulan yang ada, dapat penulis kemukakan beberapa saran terhadap "PUSAT INFORMASI PADA PERUSAHAAN DAERAH AIR MINUM(PDAM) KOTA PADANG BERBASIS WEB" Untuk Mempermudah Proses pembayaran dan tagihan pada PDAM Padang, maka penulis memberikan beberapa saran yang bertujuan untuk menyempurnakan sistem yang ada antara lain:

1 Untuk memudahkan dalam penerapan dan pengembangan website ini sebaiknya pihak organisasi perlu melakukan pengajaran dan pelatihan terhadap kasir, pelanggan serta semua yang terlibat dalam sistem dalam hal pengenalan dan pengoperasian website agar secara optimal.

2 Dalam menerapkan sistem komputerisasi sebaiknya didukung oleh perangkat yang memadai, baik dari segi manusia (brainware) maupun segi peralatannya (software dan hardware).

3 Penulis menyarankan agar dikembangkannya mengenai masalah keamanan dari sistem misalnya mengenai pengelolaan hak akses pengguna dan penambahan firewall, yaitu sebuah software program yang dipasang pada sebuah jaringan dan bertugas memproteksi sistem komputer dengan tujuan mengamankan jaringan internal.

4 Program atau aplikasi ini memang multi user tapi alangkah baiknya hanya Sub- bagian tertentu saja yang bisa mengaksesnya dan menjalankannya supaya keakuratan data itu tidak disalahgunakan oleh pihak-pihak yang tidak bertanggung jawab.

5 Program ini perlu untuk terus dipantau kinerjanya pada saat pengujian lapangan secara penuh, hingga dapat diyakini bahwa tidak terdapat masalah dalam penerapan sistem. 


\section{DAFTAR PUSTAKA}

[1]. Hirin, Virgi. 2011. Cepat Mahir Pemrograman WEB dengan PHP MySQL. Jakarta: Prestasi Pustaka

[2]. Jogiyanto. 2000 . Analisis dan Desain.Yogyakarta: Andi

[3]. Jogiyanto. 2005 . Sistem Teknologi Informasi. Yogyakarta : Andi

[4]. Kadir, Abdul. 2014. Pengenalan Sistem Informasi Edisi Revisi. YogyakartaAndi

[5]. Nugroho, Bunafit. Membuat Website Sendiri dengan PHP-MySQL. Mediakita. Jakarta 2009

[6]. Oktavian, Diar Puji.2013. Membuat Website Powerfull Menggunakan PHP. Yogyakarta : Mediakom

[7]. Wahana Komputer. 2011. Modul Pembelajaran Rekayasa Perangkat Lunak. Bandung : Graha

[8]. Westriningsih. 2013. Teknik Singkat dan Cepat Menguasai CSS3. Semarang : Wahana Komputer

[9]. Wahana Komputer.2012. Mudah Membuat Portal Berita Online Dengan PHP dan $M y S Q L$.Yogyakarta: ANDI 